\title{
SYNTHESIS OF MESOPOROUS $\gamma$-ALUMINA AND ITS CATALYTIC PERFORMANCE IN DICHLOROPROPANOL CYCLIZATION
}

\author{
Huimin Yang ${ }^{\mathrm{a}}$, Ruyue Han a and Fuxiang $\mathrm{Li}^{\mathrm{a}, *,(\mathbb{D}}$ \\ ${ }^{a}$ College of Chemistry and Chemical Engineering, Taiyuan University of Technology, Taiyuan, Shanxi Province, 030024 PR China
}

Recebido em 27/02/2019; aceito em 29/07/2019; publicado na web em 30/08/2019

\begin{abstract}
This paper discusses the synthesis and resulting catalytic performance of mesoporous alumina using aluminum isopropoxide as the aluminum source, and synthesized organosiloxane KH560-540 as template. The effects of the hydrothermal conditions, as well as the amount of templating agent at $\mathrm{pH}$ values of 5-9 on the structure of the synthesized mesoporous alumina were investigated by nitrogen adsorption-desorption methods, XRD and electron microscopy. Alumina from a rod-like scaffold structure was obtained, and the specific surface area was as high as $508 \mathrm{~m}^{2} \mathrm{~g}^{-1}$. Also, the coordination state of aluminum before and after calcination was analyzed by ${ }^{27} \mathrm{Al}-\mathrm{NMR}$ spectroscopy. The role of the templating agent in the synthesis process was determined. The synthesis mechanism of mesoporous alumina prepared by a KH560-540 template was also proposed. The acidity of samples that were synthesized by different templating agents were compared to NH3-TPD, and the content of Si in each sample was tested by ICP-OES, the results show that the silicon content has little effect on the acidity of the sample. Finally, we used the synthesized mesoporous alumina to catalyze the cyclization of dichloropropanol to epichlorohydrin, which showed excellent catalytic performance:dichlorohydrin conversion is up to $96 \%$ and epichlorohydrin yield of nearly $92 \%$.
\end{abstract}

Keywords: mesoporous $\gamma$-alumina; templating agent KH560-540; catalytic performance.

\section{INTRODUCTION}

Mesoporous alumina is a type of material with high scientific research value because it is widely used in the petrochemical industry, fine chemical production, and organic synthesis, among other fields. Wide interest in mesoporous alumina is due to its excellent structural properties and high thermal stability. ${ }^{1}$ Mesoporous alumina has many crystal structures, with each crystal phase having a different structure and properties. ${ }^{2}$ Among these structures is mesoporous $\gamma$-alumina, that shows large specific surface area, high activity, and porosity, which have important applications implications in catalysis and adsorption. ${ }^{3-5}$ Numerous research studies have been devoted to the synthesis of mesoporous alumina with high specific surface area, uniform pore size and high thermal stability. ${ }^{6,7}$ The main synthetic methods for mesoporous alumina are: hydrothermal-solvothermal synthesis, the solgel process, and evaporation induced self-assembly method..$^{8-10}$ In recent years, these specific methods have been optimized and improved in order to synthesize mesoporous alumina with specific morphlogies. ${ }^{11,12}$ For example, Zhang et al. synthesized mesoporous $\gamma$-alumina with crystalline pore walls by a vacuum-promoted self-assembly and alkaline hydrothermal method. ${ }^{13} \mathrm{Wu}$ et al. carried out the sol-gel process in an aqueous system, and the structural properties of mesoporous alumina were tuned by controlling the amount of reactants added. ${ }^{14}$ Afshar et al. also synthesized mesoporous alumina using a templateassisted sol-gel method and they studied the structural dependency of mesoporous alumina to the polymeric template content and calcination temperature. ${ }^{15}$ Wang et al. synthesized ordered mesoporous alumina with high thermal stability by using aluminum nitrate as precursor in the evaporation-induced self-assembly (EISA) pathway. ${ }^{16}$ There examples reveal that the structure and properties of the synthesized mesoporous alumina can be tuned by systematically controlling the preparation conditions and methods.

The basic principle of these synthesis methods is that the interaction between the inorganic source and the template agent

*e-mail: 163f64x@163.com generates a mesoscopic structure in a certain self-assembled method, and the mesoporous material is obtained after further processing. ${ }^{17}$ Qian et al. synthesized mesoporous alumina with different morphologies using different types of surfactants (e.g. cationic surfactant CTAB and anionic surfactant SDS), indicating that the templating agent has a certain effect on the morphology control of mesoporous alumina. ${ }^{18}$ In addition, Agneta et al. synthesized mesoporous alumina with the anionic surfactant lauric acid and the nonionic surfactant polyethyleneoxide as a template, and used continuous wave electron paramagnetic resonance (CW-EPR) together with electron spin-echo envelope modulation (ESEEM) to get information on the interaction of ionic and non-ionic surfactants with the alumina species in the synthesis of organized mesoporous alumina. The results showed that the ionic surfactant combines with the aluminum source during the hydrolysis process, and the non-ionic surfactant aids pore formation during the drying process. ${ }^{19}$ Therefore the selection and synthesis of templating agents is also one of the key factors for the preparation of mesoporous alumina.

Epichlorohydrin $(\mathrm{ECH})$ is an important intermediate in organic synthesis, it has very high value in industrial chemical production. $\mathrm{ECH}$ is mainly used for the production of epoxy resins, synthetic glycerol, chlorohydrin rubber, stabilizers and other products. ${ }^{20-23}$ At present, there are mainly three methods for producing ECH in industry: high-temperature chlorination of propylene, propylene acetate chlorination, and glycerol chlorination. These three methods have their advantages and disadvantages, but they all have the last step in the process in common: the synthesis of $\mathrm{ECH}$ by saponification of dichlorohydrin $(\mathrm{DCH}){ }^{24-26}$ In this reaction, potassium hydroxide, sodium hydroxide, and calcium hydroxide are often used as the alkaline catalysts, and the reaction form is a homogeneous reaction in the liquid phase. Since the reaction requires an excessive amount of alkali solution and produces many by-products, one main issue in the product refining process is the separation of the liquid catalyst material from the liquid product. ${ }^{27,28}$ Hence, substituting a solid catalyst for a homogeneous catalyst can solve the above problems effectively. ${ }^{29-31}$ 
In this paper, the alkyl coupling agents KH560 and KH540 were used as raw materials, and the synthetic siloxane KH560-540 was used as a template to synthesize mesoporous alumina by a hydrothermal assisted sol-gel method. The hydrothermal conditions, the template concentration and the $\mathrm{pH}$ of the mixed solution and their effects on the pore structure and morphology of the mesoporous alumina were investigated. The silane coupling agents KH560 and KH540 are inexpensive and easy to obtain. In the synthesis of KH560-540, the ring opening process of the epoxy group in the KH560 structure subsequently reacts with an amino group in KH540 to form a covalent $\mathrm{C}-\mathrm{N}$ bond, and the two are combined to obtain KH560-540. This resulting siloxane has three branches and is similar to a mesh structure. In the preparation of mesoporous alumina is easier to combine KH560-540 with the aluminum source than the commonly used single-chain linear polymer template, such as P123 and F127, because the KH560-540 molecule contains more groups and, therefore, larger binding capacity. It also occupies more space to form mesopores. It is also worth noticing that the use of waters is ideal as a non-polluting environmental synthetic medium, and the hydrothermal conditions provided by high temperature and pressure promote organic and inorganic self-assembly, which shortens the preparation time.

\section{EXPERIMENTAL}

\section{Preparation of template agent}

The templating agent, KH560-540 was synthesized using the procedure reported by Li et al. ${ }^{32}$ Alkyl coupling agents, KH-560 and KH-540 were added to a three-necked flask at a molar ratio of 2:1 respectively. The reaction was carried out at $70{ }^{\circ} \mathrm{C}$ for 8 hours under microwave conditions under a nitrogen atmosphere in order to obtain the KH560-540 monomer, which was then dissolved in methanol to form a solution with a $50 \%$ mass concentration. Figure 1 shows the equation of the reaction.

\section{Preparation of mesoporous alumina}

In a typical synthesis, $18 \mathrm{~mL}$ of distilled water were added to a beaker and heated to $80{ }^{\circ} \mathrm{C}$. Then $1.02 \mathrm{~g}$ aluminum isopropoxide was slowly added while stirring. After the aluminum isopropoxide was completely dissolved, the $\mathrm{pH}$ was adjusted with ammonia or nitric acid and the sample was stirred for $1 \mathrm{~h}$ until a milky suspension resulting from the hydrolysis of the aluminum isopropoxide was obtained. Subsequently, the template was added dropwise into the milky suspension and the mixture was stirred at room temperature for 3 hours. Finally, the mixture was poured into a $50 \mathrm{~mL}$ PTFElined hydrothermal reactor and a hydrothermal reaction was carried out. It was also dried at $80{ }^{\circ} \mathrm{C}$ and calcined at $500{ }^{\circ} \mathrm{C}$ for $4 \mathrm{~h}$ (air atmosphere, heating rate is $1{ }^{\circ} \mathrm{C} \mathrm{min}^{-1}$ ) to obtain the sample. The molar ratio of water to aluminum isopropoxide to KH560-540 was 2000:10:(0 2). The obtained samples were denoted as MA-a-b-c-d (a: template concentration; b: hydrothermal temperature $/{ }^{\circ} \mathrm{C}$; c: hydrothermal time; $\mathrm{d}: \mathrm{pH}$ ).

\section{Characterization}

\section{Nitrogen adsorption-desorption}

Nitrogen adsorption-desorption isotherms were measured at $-196{ }^{\circ} \mathrm{C}$ on a Quantachrome Nova 2000e instrument, with samples first being degassed at $150{ }^{\circ} \mathrm{C}$ for $6 \mathrm{~h}$ under vacuum. The specific surface area (SBET) was calculated using Brunauer-Emmett-Teller (BET) method. The total pore volume and pore-size distributions were calculated using the NLDFT (nonlocal density functional theory) model.

\section{$X R D$}

X-Ray diffraction (XRD) patterns were recorded on a Shimadzu XRD-6000 X-ray powder diffractometer with a $\mathrm{Cu} \mathrm{K} \alpha(\lambda=0.15418)$ and radiation $(40 \mathrm{kV}, 30 \mathrm{~mA})$ at a scanning rate of $8^{\circ} \mathrm{min}^{-1}$ in the $2 \theta$ range from $10^{\circ}$ to $80^{\circ}$.

\section{SEM}

Scanning electron microscopy (SEM) experiments were performed with a FEI NOVA-NANO electron microscope operating at $20-25 \mathrm{kV}$, using gold metallized samples.

\section{TEM and SAED}

Transmission electron micrograph (TEM) and Selected area electron diffraction (SAED) images were obtained with a Tecnai G2 F20 microscope under an acceleration voltage of $200 \mathrm{kV}$.

\section{${ }^{27} \mathrm{Al}-\mathrm{NMR}$}

The aluminum was analyzed using the Avance III 600 Nuclear magnetic resonance (NMR) instrument produced by Bruker, Switzerland. The instrument is equipped with a $3.2 \mathrm{~mm}$ magic angle probe with a test frequency of $12 \mathrm{KHz}$.

\section{$\mathrm{NH}_{3}-\mathrm{TPD}$}

$\mathrm{NH}_{3}$-TPD was tested with an AutoChem1 2920 type adsorption instrument. The test conditions were: pretreatment temperature of $400{ }^{\circ} \mathrm{C}$, adsorption temperature of $50{ }^{\circ} \mathrm{C}$, and the desorption temperature of $790{ }^{\circ} \mathrm{C}$. The carrier gas used was $\mathrm{N}_{2}$, and the reaction gas was $10 \% \mathrm{NH}_{3} / \mathrm{N}_{2}$.

\section{ICP-OES}

The content of $\mathrm{Si}$ in the prepared sample was examined using an Agilent-720 electron coupling plasma emission spectrometer. Samples (about $0.1 \mathrm{~g}$ ) were accurately weighed and placed in the digestion tube. Acid was added to the sample, and the sample digestion tube was placed in the microwave digestion apparatus for digestion. After complete digestion was completed, the sample was diluted with deionized water to the scale line of the volumetric flask and analyzed.

\section{Catalytic test}

The catalytic dichlorohydrin cyclization into epichlorohydrin using MA-0.4-120-72h-9 and industrial alumina were carried out
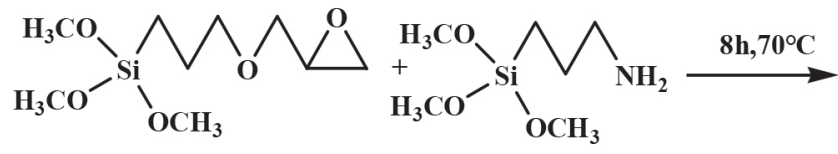

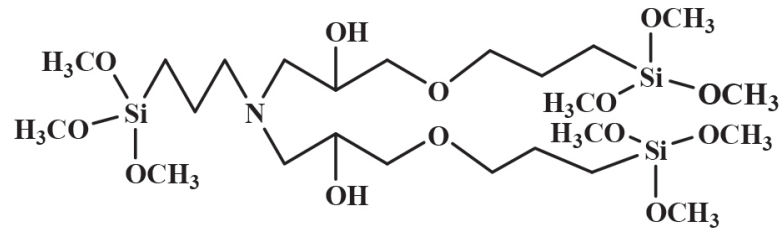

Figure 1. The synthetic scheme of organosiloxane template KH560-540 
in a fixed-bed system at atmospheric pressure. Three hundred milligrams of catalyst were first placed onto a quartz wool plug located in a quartz tube. The reactant dichlorohydrin was vaporized in the vaporizing chamber at $80{ }^{\circ} \mathrm{C}$, and carried by nitrogen gas at a flow rate of $100 \mathrm{~mL} \mathrm{~min}^{-1}$ into the reactor with a weight hourly space velocity of $1.06 \mathrm{~h}^{-1}$ to react under the action of the catalyst. The reaction products were analyzed online by gas chromatography (GC-920), using a flame ionization detector.

\section{RESULTS AND DISCUSSION}

\section{Nitrogen adsorption-desorption analysis}

\section{The influences of hydrothermal conditions}

The nitrogen adsorption-desorption isotherms and corresponding pore-size distribution curves at different hydrothermal temperatures are shown in the Figure 2a. All samples exhibit the classical shape of type IV isotherms with H3-type hysteresis loops slightly shifting to H2-type; this H2-type of hysteresis loop indicates the presence of slit-shape pores in the macro range. ${ }^{33,34}$ It can be seen that at higher the capillary condensation step shift to higher relative pressure hydrothermal temperatures as result of wider aperture distributions. This may be because the interaction between the template and the aluminum source is accelerated at high temperature. The more the templating agent is combined with the aluminum source, the larger the space occupied by it, resulting in a larger pore size. However, excessive combination leads to agglomeration and disorder in the pore channel, there by broadening the pore size distribution becomes wider. ${ }^{35}$ It is found by comparison and analysis that sample MA-12048h-9 shows a rather narrow pore size distribution. The structural parameters of the pores are as given in Table 1 and show that when the hydrothermal temperature is $120^{\circ} \mathrm{C}$, the specific surface area is also
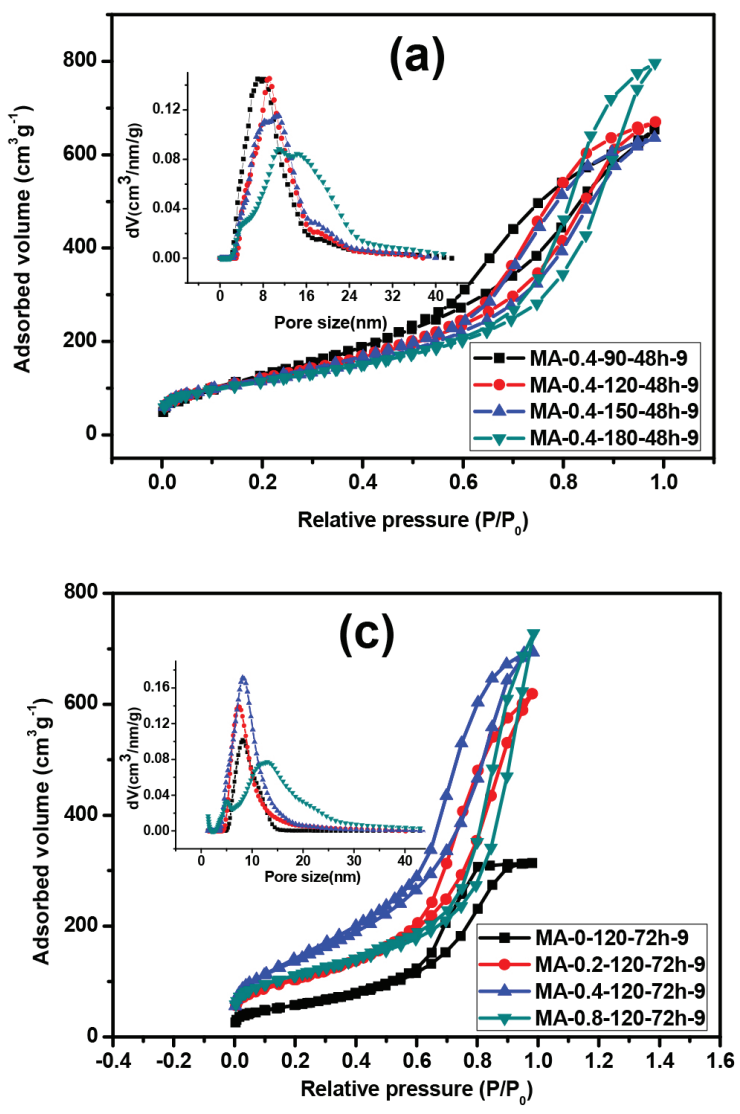

relatively large. In summary, a hydrothermal temperature of $120^{\circ} \mathrm{C}$ is appropriate for preparing mesoporous alumina.

Figure $2 \mathrm{~b}$ shows the adsorption-desorption isotherms and pore-size distribution curves of mesoporous alumina at different hydrothermal times at $120{ }^{\circ} \mathrm{C}$. It can be seen from the figure that the hydrothermal time mainly affects the steepness of the nitrogen adsorption desorption isotherms. We can also see from the Table 1 that BET specific surface area and pore volume increase with the hydrothermal time from $24 \mathrm{~h}$ to $72 \mathrm{~h}$. We speculate that the length of the hydrothermal time affects the stability of the combination of the templating agent and the aluminum source. When the hydrothermal temperature is constant, the longer the hydrothermal time, the stronger the combination of the templating agent and the aluminum source. However, if the hydrothermal time is too long, water molecules will enter the mesostructure, and the structure collapses during calcination, resulting in a decrease in specific surface area. ${ }^{36-38}$ It can be clearly seen that the curve with a hydrothermal time of $72 \mathrm{~h}$ is steeper in Figure $2 \mathrm{~b}$, combined with the information in table 1, MA-0.4-120-72h-9 has a relatively large specific surface area, so 72 hours is a preferred hydrothermal time based on the reaction conditions.

\section{The effects of template concentration}

Figure $2 \mathrm{c}$ shows the effects of template concentration on the pore structure of synthesized mesoporous alumina. It is observed that with a small increase in the template concentration (from 0 to 0.4 ), the pore volume increases from 0.48 to $0.98 \mathrm{~cm}^{3} \mathrm{~g}^{-1}$, and surface area increases from 255 to $508 \mathrm{~m}^{2} \mathrm{~g}^{-1}$. However, increasing the template amount to $0.8 \mathrm{~mL}$ results in a remarkable reduction in the adsorbed volume, and the surface area is reduced to $437 \mathrm{~m}^{2} \mathrm{~g}^{-1}$. This is because an appropriate amount of the templating agent improves the combination of the aluminum source and the templating agent, thereby increasing the pore size and specific surface area. However, if the amount of the
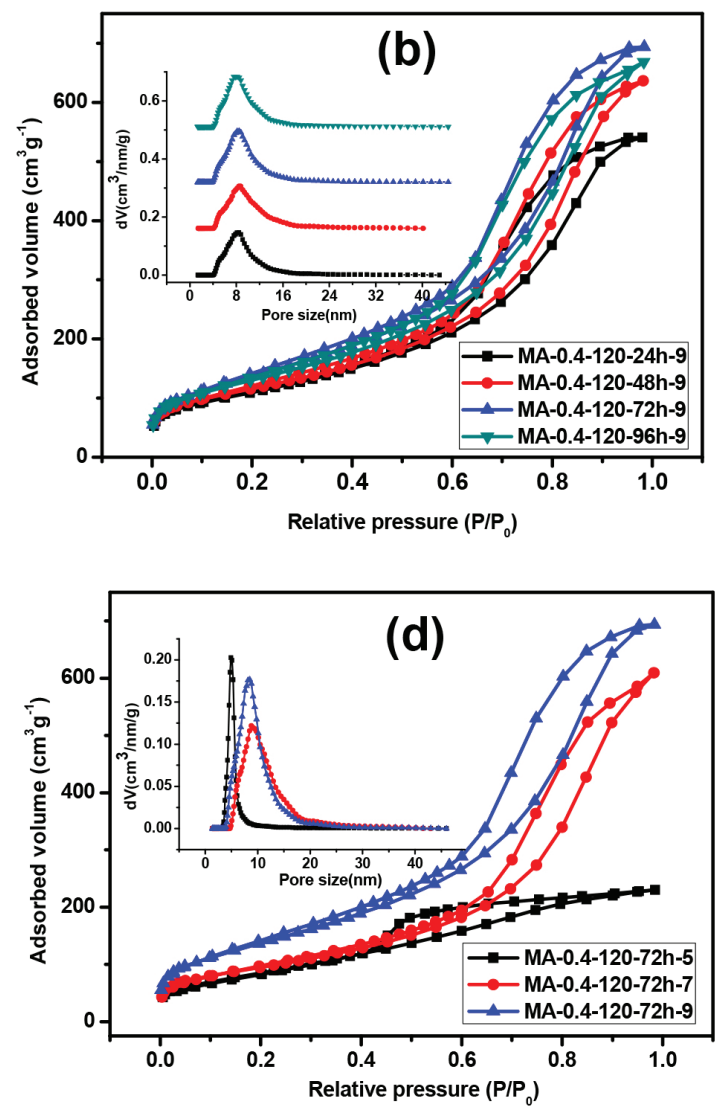

Figure 2. Nitrogen sorption isotherms and pore size distributions curves of samples synthesized under different conditions 
Table 1. The pore structure parameters of samples synthesized under different conditions

\begin{tabular}{|c|c|c|c|c|}
\hline Sample & $\begin{array}{l}\text { Total BET surface area } \\
\left(\mathrm{m}^{2} \mathrm{~g}^{-1}\right)\end{array}$ & $\begin{array}{l}\text { Total pore volume } \\
\left(\mathrm{cm}^{3} \mathrm{~g}^{-1}\right)\end{array}$ & $\begin{array}{l}\text { Most probable pore size } \\
(\mathrm{nm})\end{array}$ & $\begin{array}{l}\text { Si content } \\
(\%)\end{array}$ \\
\hline MA-0.4-90-48h-9 & 376 & 1.02 & 8.1 & -- \\
\hline MA-0.4-120-48h-9 & 411 & 0.98 & 8.1 & -- \\
\hline MA-0.4-150-48h-9 & 378 & 1.27 & 10.9 & -- \\
\hline MA-0.4-180-48h-9 & 343 & 1.36 & 14.2 & -- \\
\hline MA-0.4-120-24h-9 & 400 & 0.83 & 8.1 & -- \\
\hline MA-0.4-120-72h-9 & 508 & 1.07 & 8.1 & 2.83 \\
\hline MA-0.4-120-96h-9 & 473 & 1.03 & 8.1 & -- \\
\hline MA-0-120-72h-9 & 255 & 0.48 & 8.1 & 0.00 \\
\hline MA-0.2-120-72h-9 & 371 & 0.95 & 7.0 & 2.65 \\
\hline MA-0.8-120-72h-9 & 437 & 1.13 & 12.9 & 7.38 \\
\hline MA-0.4-120-72h-5 & 322 & 0.36 & 4.8 & -- \\
\hline MA-0.4-120-72h-7 & 345 & 0.94 & 9.4 & -- \\
\hline Industrial alumina & 200 & 0.22 & 5.0 & 0.00 \\
\hline
\end{tabular}

templating agent is too large, and the excess templating agent cannot be fully combined with the aluminum source, the self-combination prevails causing a decrease in the order in the pores, broadening of the pore size distribution, and reduction of the specific surface area.

\section{The effects of $p H$}

As can be seen in Figure 2d, pH has a great influence on the pore structure of the synthesized mesoporous alumina. When synthesized under acidic conditions, the pressure at which capillary condensation occurs is low, and the pore diameter is small; the pressure at which capillary condensation occurs in neutral and alkaline conditions is not much different, but the nitrogen adsorption desorption curve under alkaline conditions is steeper and the pore size distribution is also more centralized. Table 1 shows the pore structure parameters of mesoporous alumina synthesized at different $\mathrm{pH}$ values, it can be seen from the table that BET specific surface area and pore volume increase with $\mathrm{pH}$, and the specific surface area and pore volume of MA synthesized under alkaline conditions are relatively large. This is due to acidic conditions, favoring the production $\mathrm{AlOOH}$ while alkaline conditions favor the production of $\mathrm{Al}(\mathrm{OH})_{3} \cdot{ }^{39-41}$ Since $\mathrm{Al}(\mathrm{OH})_{3}$ contains more $\mathrm{Al}-\mathrm{OH}$ bonds than the former, it causes increased combination with templating agent.

\section{X-ray diffraction (XRD)}

Figure 3 (a d) shows the X-ray diffraction pattern of the wide angle $\left(10-80^{\circ}\right)$ area for the samples synthesized under different conditions. The XRD pattern of samples synthesized at different hydrothermal temperatures (Figure 3a) displayed diffraction peaks at $2 \theta$ of $67.1^{\circ}, 45.81^{\circ}, 39.51^{\circ}, 37.61^{\circ}, 31.91^{\circ}$ and $19.41^{\circ}$, which are indexed to $\gamma-\mathrm{Al}_{2} \mathrm{O}_{3}$ phase with cubic structure (JCPDS card 10-0425). With increased hydrothermal temperature, XRD peaks become more defined, indicating that the hydrothermal temperature mainly affects the crystallinity of the sample. Diffraction peaks of the MA-0.4-120-24h-9 in Figure 3b are indexed to the $\gamma-\mathrm{AlOOH}$ phase (JCPDS card 21-1307), which confirm that the hydrothermal time affects the crystal structure, indicating that the hydrothermal time is too short to form alumina. It can be seen from Figure $3 \mathrm{c}$ that as the concentration of the templating agent increases, the crystallinity of alumina decreases. Figure $3 \mathrm{~d}$ shows that the $\mathrm{pH}$ has less of an effect on the crystal structure. The small angle XRD pattern of samples synthesized at different $\mathrm{pH}$ values (Figure 3e) shows a weak diffraction peak around $1^{\circ}$, which demonstrates the existence of mesostructure, and the high peak intensity of sample MA-0.4-120-72h-9 indicates that its pore channel order has increased.

\section{Electron microscopy (SEM, TEM and SAED image analysis)}

SEM, TEM and SAED images of MA-120-72h-9 are illustrated in Figure 4. As can be seen clearly in Figure 3 a, the obtained $\gamma$-alumina exhibited a bulk-shaped morphology and its surface is covered with many irregular nanoparticles. Many bulk structures are overlapped and interconnected with each other and therefore generated many pore structures, the reason for this phenomenon may be that the pore structures were occupied by water during the polymerization process. The TEM image (Figure 4b) shows a scaffold structure consisting of a mixture of rod-like structures and thin sheets, with most of the rods having a length of 30-40 $\mathrm{nm}$ and a width of 2-3 nm. This illustrates that the porous structure arose from the interlacing of the rods. The HRTEM images (Figure 4c) show that the lattice fringes of $\gamma$-alumina are clearly resolved, indicating the crystallization of the material. The SAED pattern inserted in Figure $4 \mathrm{c}$ shows bright diffraction rings, further confirming the crystalline structure exhibits polycrystalline feature of this material.

\section{${ }^{27} \mathrm{Al}-\mathrm{NMR}$ analysis}

${ }^{27} \mathrm{Al}-\mathrm{NMR}$ spectrum analysis on the samples were performed before and after calcination of the samples, and with or without the addition a templating agent in order to understand the coordination state of aluminum in the sample. As shown in Figure 5, when no template is added (Figure 5a) and before calcination, the sample only shows a resonance peak near the chemical shift $(\delta)$ of 0 , and the peak near $\delta=0$ is assigned to the six-coordinate aluminum resonance peak. After calcination, the sample has three resonance peaks near the chemical shifts $(\delta)$ of $0,30,60$, corresponding to six-coordinate aluminum, five-coordinate aluminum and fourcoordinate aluminum, respectively. ${ }^{42-44}$ Also, the amount of sixcoordinate aluminum is greater than the amount of four-coordinate aluminum. After adding the templating agent (Figure 5b), and before the calcination, the sample has two resonance peaks near the chemical shifts $(\delta)$ of 0 and 60 . After calcination, the sample 

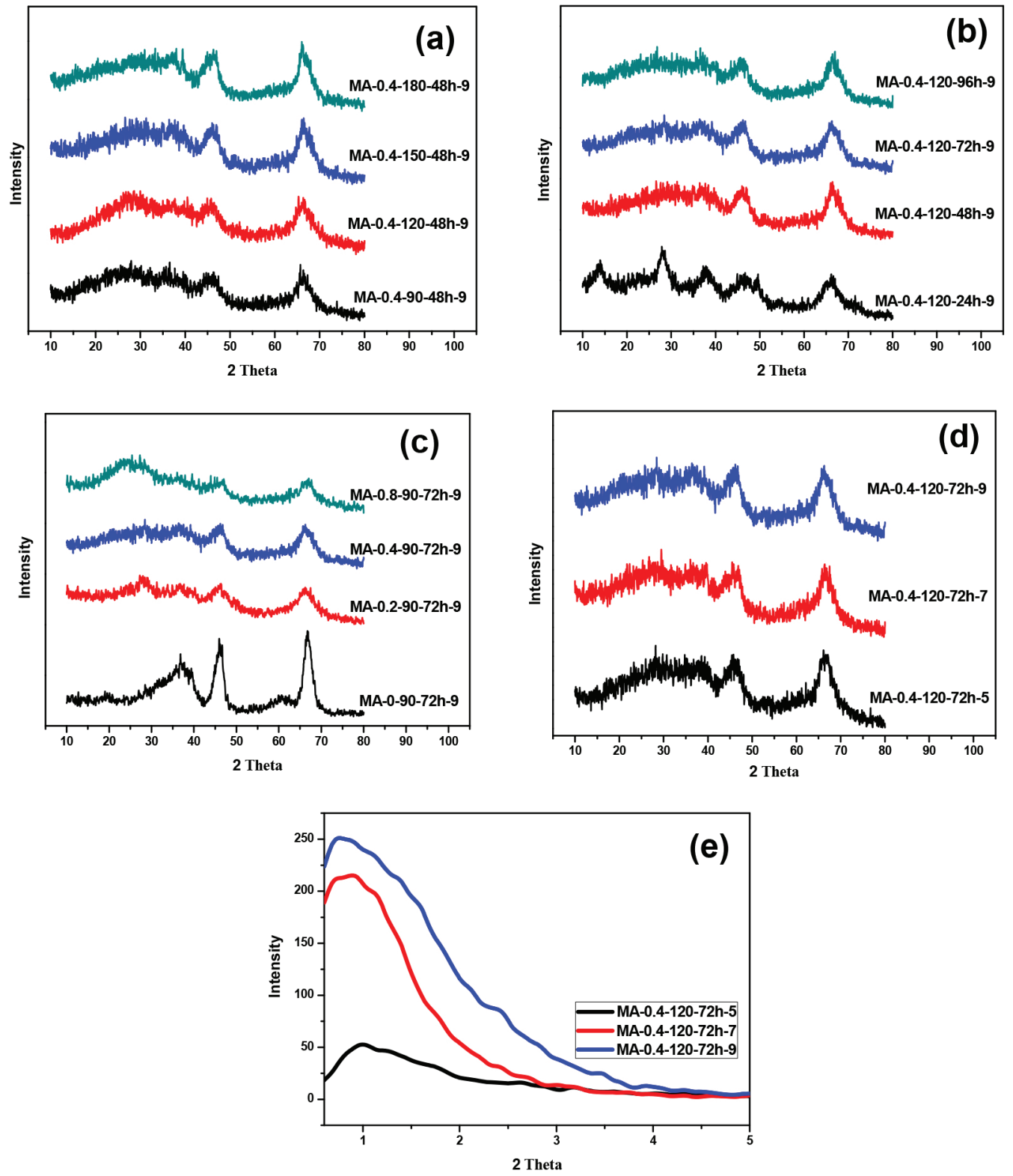

Figure 3. Wide angle XRD patters of samples synthesized under different conditions $(a, b, c, d)$ and Small angle XRD patterns of samples synthesized at different $p H(e)$
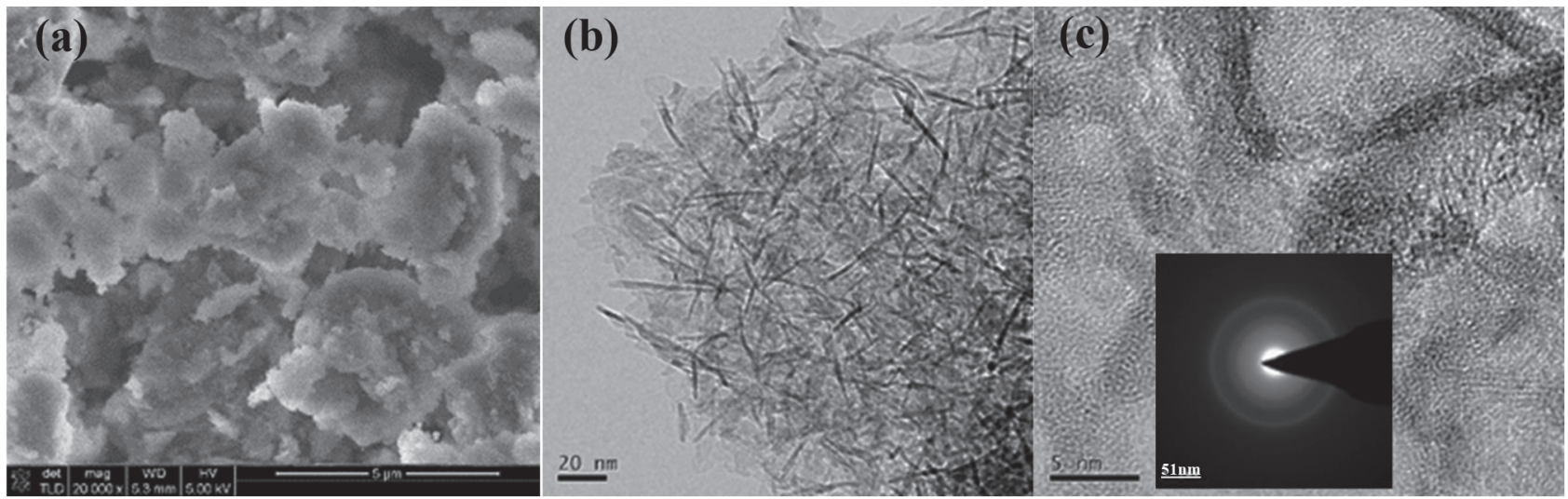

Figure 4. SEM, TEM and SAED images of MA-0.4-120-72h-9

still has peaks near the chemical shifts $(\delta)$ of $0,30,60$, but the difference is that the amount of four-coordinate aluminum is more than the six-coordinate aluminum. Comparing the two figures, the conclusion is that the sample with the added templating agent has more tetra-coordinated aluminum than the sample without the templating agent, both before and after calcination. It can 

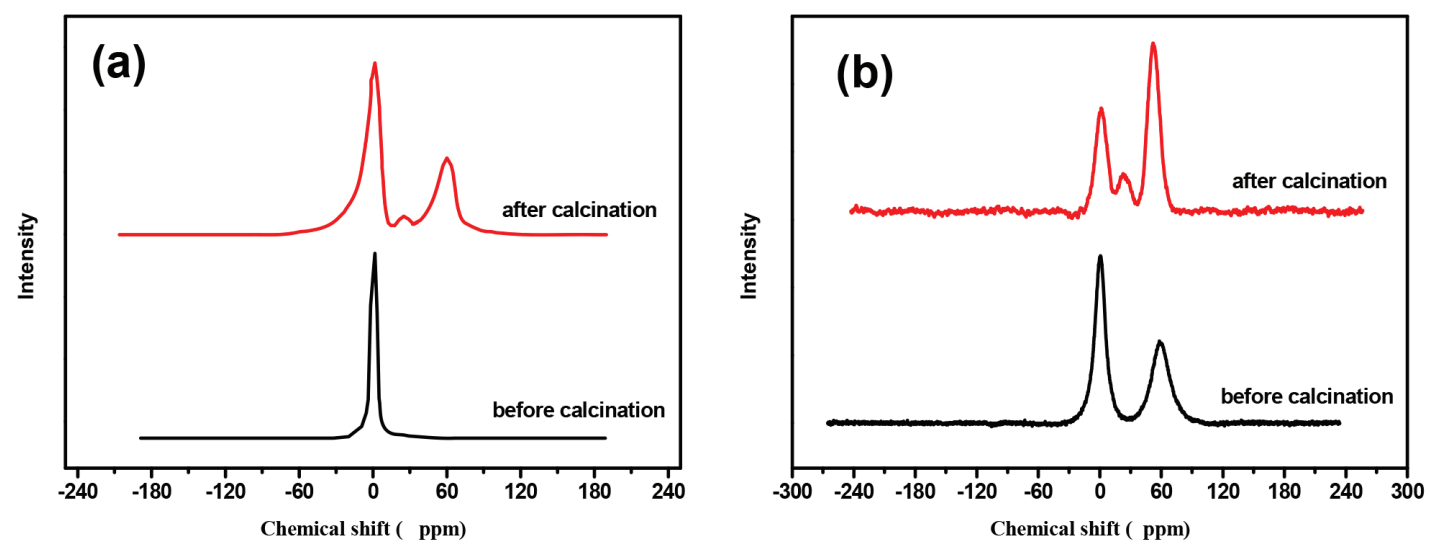

Figure 5. ${ }^{27} \mathrm{Al}$ MAS NMR of samples before and after calcination (a) without templating agent (b) with KH560-540 as templating agent

also be concluded that the excess tetra-coordinated aluminum is derived from the templating agent and the aluminum source. The tetradentate framework aluminum is formed by the connection, so it is believed that in the process of synthesizing mesoporous alumina with KH560-540 as a template, the siloxy-groups in the templating agent combine with the aluminum oxy-group produced by the hydrolysis of the aluminum source to form $\mathrm{Si}-\mathrm{O}-\mathrm{Al}$ bond; the resonance peak of the tetracoordinated aluminum is partially derived from the characteristic peak formed by the $\mathrm{Al}(\mathrm{OSi})$ boud of the $\mathrm{Al}$ atom.

Therefore, the proposed synthesis mechanism of mesoporous alumina prepared by using KH560-540 template is as follows: before the calcination, the methoxy group at the end of the template molecule is hydrolyzed to form a silicon hydroxyl, which combines with the Aluminum hydroxyl produced by hydrolysis of the aluminum source. Then, a Si-O-Al bond is formed, which constitutes the framework of mesoporous alumina, showing a smaller content of silicon (about $3 \%$ ). The long alkyl chains in the template molecule do not interact with the aluminum source, they only occupy a certain space in the skeleton framework. The calcination removes the long alkyl chains of the template to leave a final alumina structure with a mesoporous structure (Figure 6).

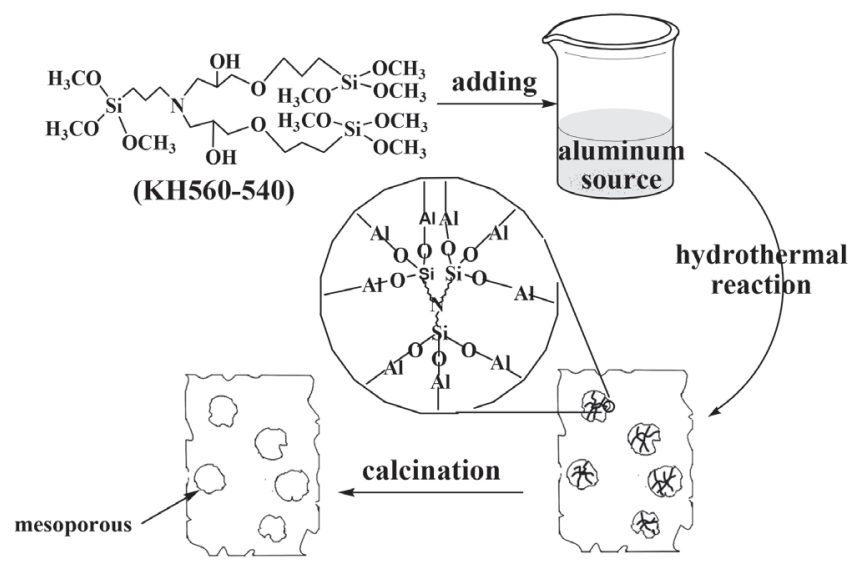

Figure 6. Synthesis mechanism of mesoporous alumina using kH560-540 as templating agent

\section{$\mathrm{NH}_{3}$-TPD and ICP-OES analysis}

The $\mathrm{NH}_{3}$-TPD patterns of the samples synthesized under different templating agent dosages are shown in Figure 7. The desorption peaks of $\mathrm{NH}_{3}$ appear in each sample at $150{ }^{\circ} \mathrm{C}$, whereas industrial alumina also exhibits an $\mathrm{NH}_{3}$ desorption peak at $300{ }^{\circ} \mathrm{C}$. The desorption peak of $\mathrm{NH}_{3}$ formerly adsorbed at weakly acidic site appears at about $150{ }^{\circ} \mathrm{C}$, while the $\mathrm{NH}_{3}$ desorption from moderately acidic sites as seen around $300{ }^{\circ} \mathrm{C}$. The peak areas represent the amount of alkali present. As seen in the figure, as the amount of templating agent increases, the amount of acid in the sample increases at first and then decreases; moreover, industrial alumina has more acid than prepared alumina. However, from the ICP-OES test results (Table 1), the content of $\mathrm{Si}$ in the sample increases with the increase in the amount of template, therefore the silicon content has little effect on the acidity of the sample.

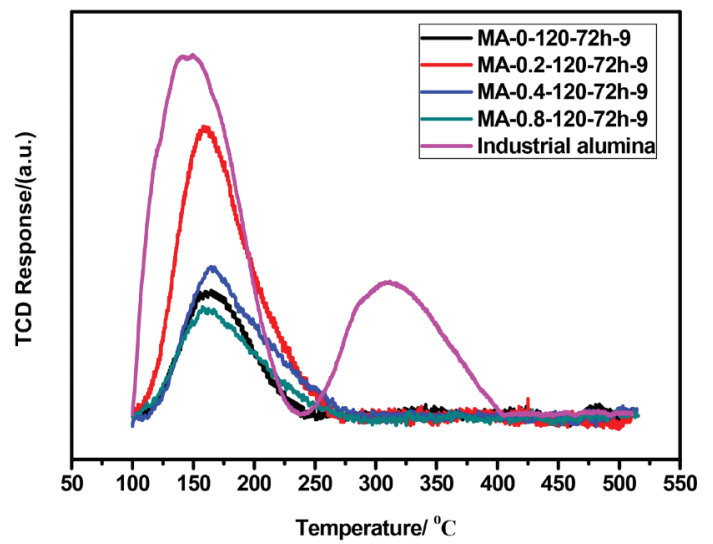

Figure 7. NH3-TPD patterns of the samples synthesized under different templating agent dosages

\section{Catalytic performance analysis}

MA-0.4-120-72h-9 with a large specific surface area $\left(508 \mathrm{~m}^{2}\right.$ $\mathrm{g}^{-1}$ ) was used as the catalyst for the reaction of dichlorohydrin cyclization into epichlorohydrin, and its catalytic performance was compared with industrial alumina. Figure 8 shows the effect of reaction temperature on the dichlorohydrin conversion, epichlorohydrin selectivity, and epichlorohydrin yield over MA0.4-120-72h-9 and industrial alumina. Notably, the dichlorohydrin conversion, the epichlorohydrin selectivity, and the epichlorohydrin yield all increase as the temperature rises. MA-0.4-120-72h-9 exhibits higher catalytic activity than industrial alumina at every reaction temperature from 150 to $330{ }^{\circ} \mathrm{C}$. The dichlorohydrin conversion is up to $96 \%$ (Figure 8a) and epichlorohydrin yield is nearly $92 \%$ at a reaction temperature of $330{ }^{\circ} \mathrm{C}$ (Figure $8 \mathrm{c}$ ). The better catalytic performance of MA-0.4-120-72h-9 may be attributed to its large specific surface area, which provides more active sites for catalyzing the dichloropropanol and thus obtaining a higher yield of epichlorohydrin. 

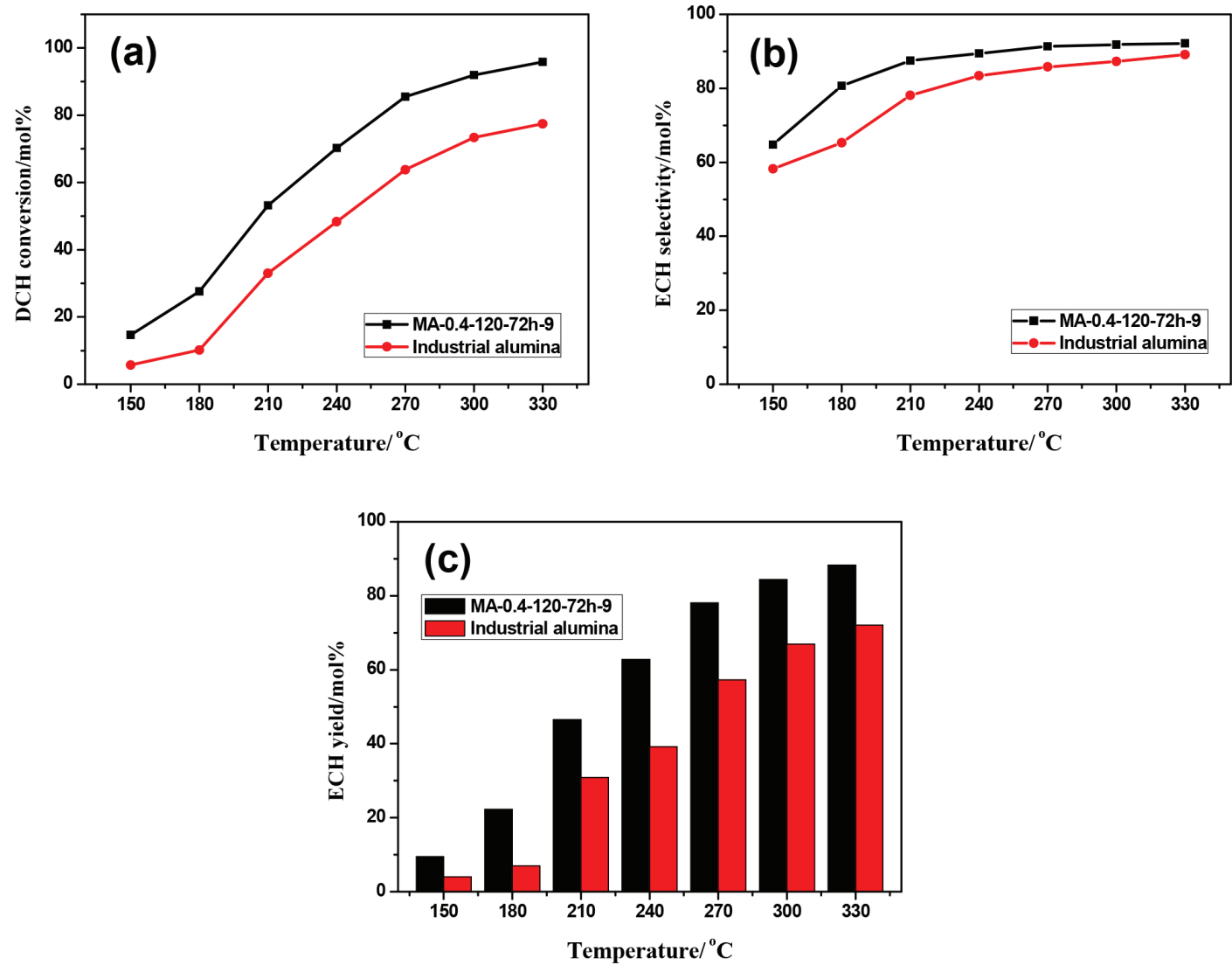

Figure 8. Effect of the reaction temperature on the DCH conversion(a), ECH selectivity(b), ECH yield(c) over MA -0.4-120-72h-9 and industrial alumina. $D C H=$ dichlorohydrin, $E C H=$ epichlorophydrin

\section{CONCLUSION}

Mesoporous $\gamma$-alumina was synthesized by using the synthesized templating agent KH560-540. The effects of hydrothermal conditions, template concentration and $\mathrm{pH}$ on the synthesis of mesoporous alumina were investigated. The results showed that the optimized conditions were: a hydrothermal temperature of $120^{\circ} \mathrm{C}$, a hydrothermal time of $72 \mathrm{~h}$, at a $\mathrm{pH}$ value of 9 , and using $0.4 \mathrm{~mL}$ of templating agent. The specific mesoporous alumina had a larger specific surface area than industrial alumina and it exhibits excellent catalytic performance in catalyzing the cyclization of dichloropropanol to epichlorohydrin. Specifically, the dichlorohydrin conversion is up to $96 \%$ and epichlorohydrin yield is at nearly $92 \%$.

\section{ACKNOWLEDGEMENT}

The project was supported by the National Natural Science Foundation of China and Natural Science Foundation of Shanxi Province.

\section{REFERENCES}

1. Bagshaw, S. A.; Pinnavaia, T. J.; Angew. Chem., Int. Ed. Engl. 1996, 35, 1102.

2. Xu, N.; Liu, Z.; Bian, S.; Dong, Y.; Li, W.; Ceram. Int. 2016, 42, 4072.

3. Kim, Y.; Kim, C.; Choi, I.; Rengaraj, S.; Yi, J.; Environ. Sci. Technol. 2004, 38, 924.

4. Morris, S. M.; Fulvio, P. F.; Jaroniec, M.; J. Am. Chem. Soc. 2008, 130, 15210

5. Lesaint, C.; Glomm, W. R.; Borg, Ø.; Eri, S.; Rytter, E.; Øye, G.; Appl. Catal., A 2008, 351, 131.
6. Yuan, Q.; Duan, H. H.; Li, L. L.; Li, Z. X.; Duan, W. T.; Zhang, L. S.; Song, W. G.; Yan, C. H.; Adv. Mater. 2010, 22, 1475.

7. Yeom, C.; Kim, Y.; Korean J. Chem. Eng. 2018, 35, 587.

8. Yuan, Q.; Yin, A.X.; Luo, C.; Sun, L.D.; Zhang, Y.W.; Duan, W.-T.; Liu, H.-C.; Yan, C. H.; J. Am. Chem. Soc. 2008, 130, 3465.

9. Chen, C.; Ahn, W.-S.; Chem. Eng. J. 2011, 166, 646.

10. Wu, Q.; Zhang, F.; Yang, J.; Li, Q.; Tu, B.; Zhao, D.; Microporous Mesoporous Mater. 2011, 143, 406.

11. Yuan, X.; Xu, S.; Lu, J.; Yan, X.; Hu, L.; Xue, Q.; Microporous Mesoporous Mater. 2011, 138, 40.

12. Huang, B.; Bartholomew, C. H.; Woodfield, B. F.; Microporous Mesoporous Mater. 2014, 183, 37.

13. Zhang, W.; Wang, Y.; Xie, M.; Guo, X.; Mater. Lett. 2016, 163, 122.

14. Wu, W.; Wan, Z.; Zhu, M.; Zhang, D.; Microporous Mesoporous Mater. 2016, 223, 203.

15. Taromi, A. A.; Kaliaguine, S.; Microporous Mesoporous Mater. 2017, $248,179$.

16. Wang, X.; Pan, D.; Xu, Q.; He, M.; Chen, S.; Yu, F.; Li, R.; Mater. Lett. 2014, 135, 35.

17. Sicard, L.; Lebeau, B.; Patarin, J.; Kolenda, F.; Oil Gas Sci. Technol. 2003, 58,567 .

18. Liu, Q.; Wang, A.; Wang, X.; Zhang, T.; Microporous Mesoporous Mater. 2007, 100, 35 .

19. Caragheorgheopol, A.; Rogozea, A.; Ganea, R.; Florent, M.; Goldfarb, D.; J. Phys. Chem. C 2009, 114, 28.

20. Singh, G. S.; Mollet, K.; D'hooghe, M.; De Kimpe, N.; Chem. Rev. 2012, 113, 1441.

21. Nouailhas, H.; Aouf, C.; Le Guerneve, C.; Caillol, S.; Boutevin, B.; Fulcrand, H. J. Polym. Sci., Part A: Polym. Chem. 2011, 49, 2261.

22. Ono, D.; Masuyama, A.; Okahara, M.; J. Org. Chem. 1990, 55, 4461. 
23. Nakano, T.; Ikawa, N.; Ozimek, L.; J. Agric. Food Chem. 2004, 52, 7555.

24. Wang, L.; Liu, Y.; Xie, W.; Zhang, H.; Wu, H.; Jiang, Y.; He, M.; Wu, P.; J. Catal. 2007, 246, 205.

25. Park, J.; Jiang, Q.; Feng, D.; Mao, L.; Zhou, H. C.; J. Am. Chem. Soc. 2016, 138, 3518 .

26. Fedushkin, I. L.; Skatova, A. A.; Chudakova, V. A.; Fukin, G. K.; Angew. Chem., Int. Ed. 2003, 42, 3294.

27. Almena, A.; Martín, M.; Ind. Eng. Chem. Res. 2015, 55, 3226.

28. Krzy anowska, A.; Milchert, E.; Chem. Pap. 2013, 67, 1218.

29. Hattori, H.; Appl. Catal., A 2015, 504, 103.

30. Hou, X.; Fu, Y.; Zhu, X.; Yin, H.; Wang, A.; Asia-Pac. J. Chem. Eng. 2015, 10, 626 .

31. Lu, Y.; Li, T.; Wang, R.; Luo, G.; Chin. J. Chem. Eng. 2017, 25, 301.

32. Li, B.; Song, G.; Wu, Y.; Li, F.; Xue, J.; Lv, Z.; J. Porous Mater. 2017, 24, 1673.

33. Cranston, R. t.; Inkley, F.; Adv. Catal. 1957, 9, 143.
34. Sing, K. Colloids Surf., A 2001, 187, 3.

35. Zhang, Z.; Han, Y.; Zhu, L.; Wang, R.; Yu, Y.; Qiu, S.; Zhao, D.; Xiao, F. S.; Angew. Chem., Int. Ed. 2001, 40, 1258.

36. Park, H.; Yang, S. H.; Jun, Y.-S.; Hong, W. H.; Kang, J. K.; Chem. Mater. 2007, 19, 535.

37. Gu, Y.; Hacarlioglu, P.; Oyama, S. T.; J. Membr. Sci. 2008, 310, 28.

38. Ungureanu, A.; Dragoi, B.; Hulea, V.; Cacciaguerra, T.; Meloni, D.; Solinas, V.; Dumitriu, E.; Microporous Mesoporous Mater. 2012, 163, 51.

39. Janicke, M.; Kumar, D.; Stucky, G.; Chmelka, B.; Stud. Surf. Sci. Catal. 1994, 84, 243.

40. Kim, Y.; Kim, C.; Kim, P.; Yi, J.; J. Non-Cryst. Solids 2005, 351, 550.

41. Khalil, K. M.; Appl. Surf. Sci. 2008, 255, 2874.

42. Vaudry, F.; Khodabandeh, S.; Davis, M. E.; Chem. Mater. 1996, 8, 1451.

43. Yao, N.; Xiong, G.; Zhang, Y.; He, M.; Yang, W.; Catal. Today 2001, 68, 97.

44. Abidli, A.; Hamoudi, S.; Belkacemi, K.; Dalton Trans. 2015, 44, 9823. 